\title{
Health Effects on Canteen Staff Working in a University Canteen
}

\author{
Penpatra Sripaiboonkij*, Sasitorn Taptakarnporn \\ Faculty of Public Health, Thammasat University, Bangkok, Thailand \\ Email: sripaiboonkijpor@hotmail.com, sasitapp@gmail.com
}

Received 6 August 2014; revised 21 September 2014; accepted 6 October 2014

Copyright (C) 2014 by authors and Scientific Research Publishing Inc.

This work is licensed under the Creative Commons Attribution International License (CC BY). http://creativecommons.org/licenses/by/4.0/

\section{(c) (7) Open Access}

\begin{abstract}
Background: Working in a canteen will involve more than one activity e.g. cutting, grinding, washing. These activities may lead to stress and muscle fatigue. Objective: To analyze health effects in canteen staff working at the university. Methods: A cross-sectional study was conducted in canteen staff. A questionnaire was used to compare the level of feeling e.g. strength, force, interest before and after work between canteen staff using a subjective judgment scale from 1-10, together with assessing muscles: extensor of the wrist, biceps, triceps at different times by using surface electromyography (EMG). A paired t-test was used to analyze data. Results: 23 canteen staff participated the project $(100 \%)$. Canteen staff did not report any significant difference in feelings e.g. freshness, keenness, force or strength that differentiated before work and after work. Extensor of the wrist seems to be the most muscle using part in a canteen activity. Conclusions: Stress levels related to working in a university canteen are low as is muscle fatigue measured by EMG. However, performing repetitive work in a canteen could lead to muscle fatigue or stress so break interval time may be important for preventing muscle fatigue and reducing stress.
\end{abstract}

\section{Keywords}

Canteen Staff, Fatigue, EMG, Feeling

\section{Introduction}

Classic problems due to working in kitchens or canteens are lower back pain, musculoskeletal disorders and stress [1]-[9].

This may be because workers have to perform several activities e.g. cutting, grinding, rolling or washing in a small area in addition to stress relating to time constraints and consequent pressure. Musculoskeletal problems

"Corresponding author. 
are also reported in cooks who work in a restricted workspace [10] [11].

The university canteen is mainly used by students and staff at breakfast and lunchtime. Task activities in a university canteen may differ from commercial kitchens because commercial kitchens may have higher workload with more demands from customers leading to increased stress and muscle fatigue. Normally, cooking and washing tasks in university canteens are done manually without modern cooking facilities. As mentioned earlier, when working in a canteen the continued use of hands and upper arm muscles (biceps, triceps) could leading to muscle fatigue and stress increased by limited working space and time constraints.

It is difficult to forecast when muscles will become fatigued and which muscles will have the most demand placed on them because this will depend on activities, the load placed on the muscles and the way the muscles compensate for strain.

Fatigue is measured by the decrease in force that occurs after repeated muscle stimulation or continuous work pushes muscles beyond their working capacity. The extent of fatigue depends on the individual, their fitness and training.

One way to analyze muscle fatigue is using electromyography (EMG) technique to measure the frequency in skeletal muscles. EMG is particularly appealing because it is a non-invasive technique for measuring muscle electrical activity resulting from contraction and relaxation.

The analysis of muscle fatigue could bring useful information concerning clinical problems, and muscle strength. The evaluation of muscle fatigue is carried out using surface electrodes and is straightforward to perform. The results obtained will be useful for managing shift patterns and reducing muscle strain.

The objective of this study was to analyze health effects in canteen staff.

\section{Methodology}

\subsection{Study Population}

A cross-sectional study was conducted at a university canteen. Study populations were canteen staff working for the university (serving mainly students, lecturers and university staff). Personal data information was obtained through interview questionnaires. Participants have been working in the canteen at least 6 months, aged of subjects were varied ranged from 17 - 64 years old. None of the subjects reported having any history of musculoskeletal pain in the previous year. 23 canteen staff were recruited to participate in the project (100\% response). All subjects were asked to sign a consent form before participating in the project. The study was approved by the Ethical committee, Thammasat University, Thailand.

The university canteen consists of several small kitchens. The university canteen provides several dishes e.g. rice, noodles, dessert and drinks. Canteen staff come to work at different times; some of them start working from 05.00 a.m., preparing materials, recipes, menus and resources for cooking, while others start work at 10.00 a.m to prepare the food and drink.

\subsection{Questionnaire}

All participants were asked to answer an interview questionnaire. The interview questionnaire included personal information, length of employment, activities/task in kitchen, self-estimated job fatigue in activities e.g. cutting, washing, changing money (level 1 = least, level 5 = the most), bi-polar self-estimated emotion feeling before work and after work in the kitchen (level 1-10); the emotion feelings consist of; freshness-fatigue, alertnesssleepy, force-exhausted, strength-weakness, interest-lack of interest, keenness-boredom, vibrant-dull.

The purpose of the study was explained to participants prior to completing the interview questionnaire.

\subsection{EMG Measurement}

Electromyography (EMG) measurements were obtained for all participants purposed to measure muscle frequency for analyzing muscle fatigue.

Measurements were taken from the extensor of the wrist and upper arms of participants. They were asked to sit comfortably on a bench in the canteen, the skin was prepared by wiping it with alcohol to ensure it was free from lotion or sweat and surface electrodes were placed on the skin.

EMG signals were recorded from 3 muscles; extensor of the wrist, triceps and biceps by using $\mathrm{Ag} / \mathrm{AgCl}$ surface electrode (blue sensors). 3 surface electrodes were placed to cover muscle with a 3rd over the bone to 
ground it. Surface electrodes were placed on either the left or right side individually. Surface electrodes were placed on the skin for about 1 minute. A standard surface electrode location was define as described by Mega 6000, model: Muscle Tester, serial number Q2010311. Volunteers were asked to place surface electrodes 3 times; morning (9.00-10.00 a.m.), afternoon (13.00 p.m. ish) and after they finished routine work in the late afternoon (approx 16.00 p.m.)

Analyzing the shift in the median frequency of the surface EMG power spectrum is a well-known method of assessing muscle fatigue. Therefore a decrease in the median power frequency serves as an index of fatigue.

\subsection{Data Analysis}

Descriptive analysis was used to describe the characteristics of the study population e.g. age, education, marital status, levels of fatigue and feeling for the canteen staff at the university canteen. Again, this was carried out at different times; before work and after work in each day. A median frequency from an EMG measurement was used to analyze the state of muscle fatigue.

A paired t-test was used to analyze data and compare the feeling of participants before and after work.

\section{Results}

All 23 canteen staff ( 6 males and 17 females) responded, giving a response rate of $100 \%$. The age range was 17 - 64 years old. Most of the participants were non-smokers with a low level of education. Characteristics of the study population are shown in Table 1.

The information relating to feelings; freshness-fatigue, alertness-sleepy, force-exhausted, strength-weakness, interest-lack of interest, keenness-boredom, vibrant-dull of subjects at different times were ranked from 1-10 (1 $=$ the least, $10=$ the most). The levels of feeling were analyzed by a paired t-test to compare the feeling of subjects before and after work. The results are shown in Table 2. Participants did not demonstrate significant differences in their feelings at different times of day including before work compared with after work. Based on averages reported, participants reporting lower than a 7 did not feel especially stressed or fatigued at work in the university canteen.

Table 1. Characteristics of study population.

\begin{tabular}{|c|c|c|c|}
\hline \multirow{2}{*}{ Personal information } & \multicolumn{2}{|c|}{ Gender } & \multirow{2}{*}{$\begin{array}{c}\text { Total } \\
23(100 \%)\end{array}$} \\
\hline & Males $(n=6)$ & Females $(\mathrm{n}=17)$ & \\
\hline \multicolumn{4}{|l|}{ Age (years) } \\
\hline - Less than 20 & 0 & $3(17.65)$ & 3 (13.04) \\
\hline - $\quad 20-29$ & $3(50)$ & $2(11.76)$ & $5(21.74)$ \\
\hline - $\quad 30-39$ & $2(33.33)$ & $3(17.65)$ & 5 (21.74) \\
\hline - $40-49$ & 0 & $6(35.29)$ & $6(26.09)$ \\
\hline - $\quad \geq 50$ & $1(16.67)$ & $3(17.65)$ & 4 (17.39) \\
\hline \multicolumn{4}{|l|}{ Education level } \\
\hline - Primary school & $3(50)$ & $8(47.07)$ & $11(47.83)$ \\
\hline - High school & $2(33.33)$ & $6(35.29)$ & $8(34.78)$ \\
\hline - Vocational & 0 & $1(5.88)$ & $1(4.35)$ \\
\hline - Bachelor degree & $1(16.67)$ & $2(11.76)$ & $3(13.04)$ \\
\hline \multicolumn{4}{|l|}{ Smoking behaviour } \\
\hline - Yes-current & $2(33.33)$ & 0 & $2(8.70)$ \\
\hline - Yes-past & $1(16.67)$ & 0 & $1(4.35)$ \\
\hline - Never & $3(50)$ & $17(100)$ & 20 (86.95) \\
\hline
\end{tabular}


Table 2. The levels of feeling before and after work of subjects.

\begin{tabular}{ccccccccccc}
\hline Feeling & $\begin{array}{c}\text { Before work } \\
\text { in the morning }\end{array}$ & $\begin{array}{c}\text { After work in } \\
\text { the morning }\end{array}$ & p-value & $\begin{array}{c}\text { Before work } \\
\text { (lunch) }\end{array}$ & $\begin{array}{c}\text { After work } \\
\text { (lunch) }\end{array}$ & p-value & $\begin{array}{c}\text { Before work in After work } \\
\text { the morning }\end{array}$ & $\begin{array}{c}\text { (lunch) } \\
\text { p-value }\end{array}$ \\
\hline Freshness-fatigue & 7.87 & 7.70 & 0.73 & 7.67 & 8.13 & 0.19 & 7.87 & 8.13 & 0.55 \\
Alertness-sleepy & 8.17 & 7.87 & 0.52 & 7.76 & 8.04 & 0.38 & 8.17 & 8.04 & 0.78 \\
Force-exhausted & 8.61 & 7.91 & 0.11 & 8.00 & 7.87 & 0.92 & 8.61 & 7.87 & 0.14 \\
$\begin{array}{c}\text { Strength-weakness } \\
\begin{array}{c}\text { Interest- } \\
\text { lack of interest }\end{array}\end{array}$ & 8.48 & 7.91 & 0.15 & 8.38 & 7.87 & 0.11 & 8.48 & 7.87 & 0.18 \\
Keenness-boredom & 8.04 & 8.43 & 0.14 & 8.76 & 8.48 & 0.14 & 9.04 & 8.48 & 0.17 \\
Vibrant-dull & 8.91 & 8.26 & 0.09 & 8.29 & 8.52 & 0.35 & 8.91 & 8.52 & 0.36 \\
\hline
\end{tabular}

It was noted participants reported a feeling of less force, strength, interest, keenness and vibrant after work in the morning compared to before work in the morning, but this was not statistically significant.

Interestingly, subjects reported they had a higher levels of freshness and alertness after work (lunch) than before work (lunch) and this was also higher than participants who would start work in the morning, but again, this difference was not statistically significant. When asked about these increased levels, participants reported being happy to finish work and go home which appeared to give them a motivational boost.

The association between activities in the kitchen and levels of fatigue were also studied. Subjects were asked to report the level of fatigue ranked 1 (least)-5 (most), based on daily activities. The results are shown in Table 3.

Results from Table 3 show subjects did not report muscle fatigue while working in the university canteen. While cooking and washing can be demanding for muscles, the levels of fatigue reported were 1.95 and 1.74 respectively.

EMG was used to measure muscle signals for all participants and these measurements were taken from the extensor of the wrist, biceps brachii muscle and triceps brachii muscle on the side of the body used most predominantly. Figure 1 shows results of muscles used at different times of day-morning, afternoon and just before finishing work. The results do not reveal a correlation between time of day and when muscles work hardest because this is largely activity dependent; some kitchens start work from 05.00 a.m. while some kitchens start work from 10.00 a.m. and finish later. From a selection of people working in ice cream, noodle, rice curry and drink kitchens the median EMG frequency signals (Figure 1), results show that participants seemed to have muscle fatigue at lunch time except a participant who worked in a drink kitchen.

\section{Discussion}

The main objective of this study was to investigate the health effects on canteen staff working in a university canteen. Participants in our study were eligible to take part if they had worked in the canteen for at least 6 months. This study had $100 \%$ feedback from participants eliminating the possibility of selection bias.

The assessment was based on a subjective judgment scale on the level of fatigue and feeling; freshness-fatigue, alertness-sleepy, force-exhausted, strength-weakness, interest-boredom, keenness-lack of interest, vibrantdull; before work and after work, in addition to objective EMG signal measurements. Consistent results were obtained that showed an association between feeling and EMG signals for analyzing muscle fatigue.

Results from the present study showed an association between the subjective level of fatigue from working in a university canteen and muscle fatigue analyzed by EMG.

\subsection{Health Effects in Canteen Staff}

Peak activity times in the university canteen are morning breakfast and lunch time. Working in a university canteen is complex; there are numerous cooking tasks, various demands from students and staff and the work is completed in a small area due to space limitations so that the working environment is humid and warm. As noted earlier, such conditions could be stressful for staff. 
Table 3. The association between the level of fatigue and daily activities.

\begin{tabular}{cc}
\hline Task activities & Levels of fatigue \\
\hline Cut vegetables, meat, or resources for food & 1.39 \\
Wash vegetable, meat or other resources & 0.94 \\
Cooking & 1.95 \\
Scoop food to dish & 1.70 \\
Serve food to customers & 1.43 \\
Changing money & 0.91 \\
Washing e.g. bowl, dishes & 1.74 \\
\hline
\end{tabular}

Remark: 1 = least fatigue, 5 = most fatigue.
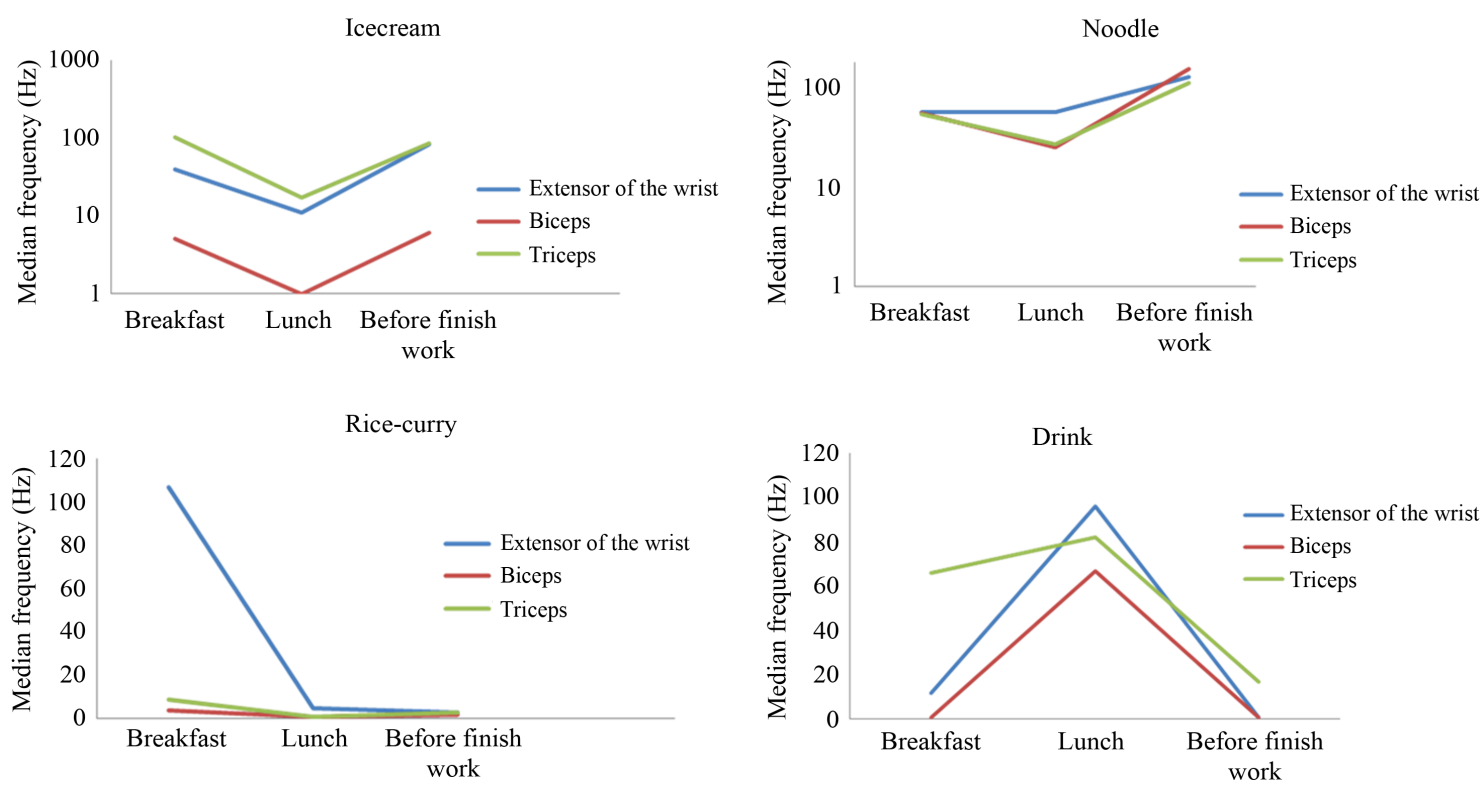

Figure 1. Selected participants worked at different kitchen show different value of median frequency depends on activities performed in kitchens.

More women than men work in the university canteen which is consistent with general statistics that women are more likely to work in a kitchen than men. From previous studies, musculoskeletal pain including low back pain seems to be a problem in women more than men [12] [13]. Subjects whom stand up for long time during food preparation could lead to effects on subjective discomfort among cooks during food preparation [14].

Working in a kitchen environment with time constraints can be stressful for staff, because they are often working hard to provide good service to customers while working within a warm humid environment. Humidity and hot kitchen conditions could directly increase stress levels for staff [6] [9] [15] [16]. However, if the work is managed to avoid high intensity periods and some relaxation intervals are provided during the day then muscle fatigue and other stress factors could be reduced.

While canteen staff do not report weakness, boredom, or feelings of exhaustion at the end of the day this maybe due to the fact staff their mood is lifted by the idea of finishing work and going home.

However, whatever the reason, the feelings reported at the end of the day differ from the initial hypothesis that participants would demonstrate negative feelings at the end of the day due to muscle fatigue. It should be noted, the university canteen used in this study was relatively small and its customers were a relatively small number of health sciences students and staff in the Schools of the Health Sciences Group only. 


\subsection{Association between Muscle Fatigue and Working Time}

In the study, we investigate the fatigue in arm muscles using EMG recording signals. We found that the state of the muscle depended on which activities the participants had carried out in the canteen. High median frequencies were found amongst canteen staff who worked during high peaks of activity. The use of EMG measurements for assessing muscle fatigue in canteen staff should be performed immediately after they stop working or resting otherwise, muscle signals stimulated by the body will quickly return to normal and the EMG measurement may not be able to detect any signals.

Prolonged activation of muscle tissue could lead to loss of force in addition to slow response rates. Participants in this study did not demonstrate either muscle fatigue or associated negative feelings. When participants completed repetitive tasks in the morning or afternoon a high peak median frequency was discovered but this was not accompanied by any negative feelings, e.g., weak, bored, lack of interest.

This could also be dependent on activities in the canteen, e.g. cutting, chopping, or grinding. Previous studies found upper arm muscles also perform repetitive tasks when working in kitchens [6]-[8] which can lead to muscle fatigue. To prevent muscle fatigue, canteen staff should be trained to work safely and use equipment appropriately to reduce and prevent muscle strain.

The main limitation of the study was the small study population at the university canteen. It is also difficult to isolate muscle fatigue because several different tasks are undertaken in the same day but EMG measurements did give an indication of which muscles had been used.

\section{Conclusions}

Canteen staff at the university appeared happy in their work based on the fact they did not experience strong negative feelings or display any obvious signs of muscle fatigue.

To maintain a good working environment and to prevent muscle fatigue and stress from arising in future occupational health management might be considered.

\section{Acknowledgements}

This work was supported by Thammasat University, Thailand. We would like to thank the canteen staff who participated in the project and Thammasat University to support grants for the study.

\section{Conflicts of Interest}

The authors declare that they have no conflicts of interest.

\section{Authors' Contributions}

PS: conception and study design, data collection, analysis and interpretation of data and writing the manuscript, funding application. ST: study design and writing manuscript.

\section{References}

[1] Ono, Y., Shimaoka, M., Hiruta, S., et al. (1997) Low Back Pain among Cooks in Nursery Schools. Industrial Health, 35, 194-191. http://dx.doi.org/10.2486/indhealth.35.194

[2] Nagasu, M., Sakai, K., Ito, A., et al. (2007) Prevalence and Risk Factors for Low Back Pain among Professional Cooks Working in School Lunch Services. BMC Public Health, 7, 171-181. http://dx.doi.org/10.1186/1471-2458-7-171

[3] Courtney, T.K., Verma, S.K., Huang, Y.H., et al. (2010) Factors Associated with Worker Slipping in Limited-Service Restaurants. Injury Prevention, 16, 36-41. http://dx.doi.org/10.1136/ip.2009.022749

[4] Verma, S.K., Chang, W.R., Courtney, T.K., et al. (2010) Workers’ Experience of Slipping in U.S. Limited-Service Restaurants. Journal of Occupational and Environmental Hygiene, 7, 491-500. http://dx.doi.org/10.1080/15459624.2010.486693

[5] Verma, S.K., Chang, W.R., Courtney, T.K., et al. (2011) A Prospective Study of Floor Surface, Shoes, Floor Cleaning and Slipping in US Limited-Service Restaurant Workers. Occupational and Environmental Medicine, 68, 279-285. http://dx.doi.org/10.1136/oem.2010.056218

[6] Haukka, E., Leino-Arjas, P., Ojajärvi, A., et al. (2011) Mental Stress and Psychosocial Factors at Work in Relation to 
Multiple-Site Musculoskeletal Pain: A Longitudinal Study of Kitchen Workers. European Journal of Pain, 15, 432438. http://dx.doi.org/10.1016/j.ejpain.2010.09.005

[7] Kokane, S. and Tiwari, R.R. (2011) Occupational Health Problems of Highway Restaurant Workers of Pune, India. Toxicology Industrial and Health, 27, 945-948. http://dx.doi.org/10.1177/0748233711399322

[8] Haukka, E., Ojajärvi, A., Takala, E.P., et al. (2012) Physical Workload, Leisure-Time Physical Activity, Obesity and Smoking as Predictors of Multisite Musculoskeletal Pain. A 2-Year Prospective Study of Kitchen Workers. Occupational and Environmental Medicine, 69, 485-492. http://dx.doi.org/10.1136/oemed-2011-100453

[9] Bhatt, H. and Sidhu, M.K. (2012) Physiological Stress Assessment of Female Workers at Kitchen Workstation. Work, 41, 441-446.

[10] Pekkarinen, A. and Anttonen, H. (1988) The Effect of Working Height on the Loading of the Muscular and Skeletal Systems in the Kitchens of Workplace Canteens. Applied Ergonomics, 19, 306-308. http://dx.doi.org/10.1016/0003-6870(88)90079-8

[11] Pehkonen, I., Miranda, H., Haukka, E., et al. (2009) Prospective Study on Shoulder Symptoms among Kitchen Workers in Relation to Self-Perceived and Observed Work Load. Occupational and Environmental Medicine, 66, 416-423. http://dx.doi.org/10.1136/oem.2008.043349

[12] Haukka, E., Leino-Arjas, P., Solovieva, S., et al. (2006) Co-Occurrence of Musculoskeletal Pain among Female Kitchen Workers. International Archives of Occupational and Environmental Health, 80, 141-148. http://dx.doi.org/10.1007/s00420-006-0113-8

[13] Tomita, S., Muto, T., Matsuzuki, H., et al. (2013) Risk Factors for Frequent Work-Related Burn and Cut Injuries and Low Back Pain among Commercial Kitchen Workers in Japan. Industrial Health, 51, 297-306. http://dx.doi.org/10.2486/indhealth.2012-0134

[14] Iwakiri, K., Kunisue, R., Sotoyama, M., et al. (2008) Postural Support by a Standing Aid Alleviating Subjective Discomfort among Cooks in a Forward-Bent Posture during Food Preparation. Journal of Occupational Health, 50, 57-62. http://dx.doi.org/10.1539/joh.50.57

[15] Chang, H.-J., Kim, J.-W., Ju, S.-Y., et al. (2012) How Do the Work Environment and Work Safety Differ between the Dry and Wet Kitchen Foodservice Facilities? Nutrition Research and Practice, 6, 366-374. http://dx.doi.org/10.4162/nrp.2012.6.4.366

[16] Matsuzuki, H., Haruyama, Y., Muto, T., et al. (2013) Workers’ Load and Job-Related Stress after a Reform and Work System Change in a Hospital Kitchen in Japan. Environmental Health and Preventive Medicine, 18, 171-176. http://dx.doi.org/10.1007/s12199-012-0291-9 
Scientific Research Publishing (SCIRP) is one of the largest Open Access journal publishers. It is currently publishing more than 200 open access, online, peer-reviewed journals covering a wide range of academic disciplines. SCIRP serves the worldwide academic communities and contributes to the progress and application of science with its publication.

Other selected journals from SCIRP are listed as below. Submit your manuscript to us via either submit@scirp.org or Online Submission Portal.
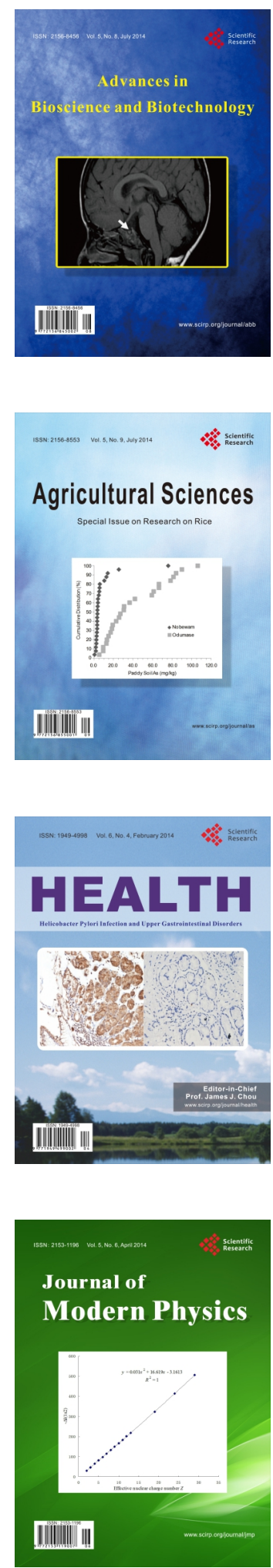
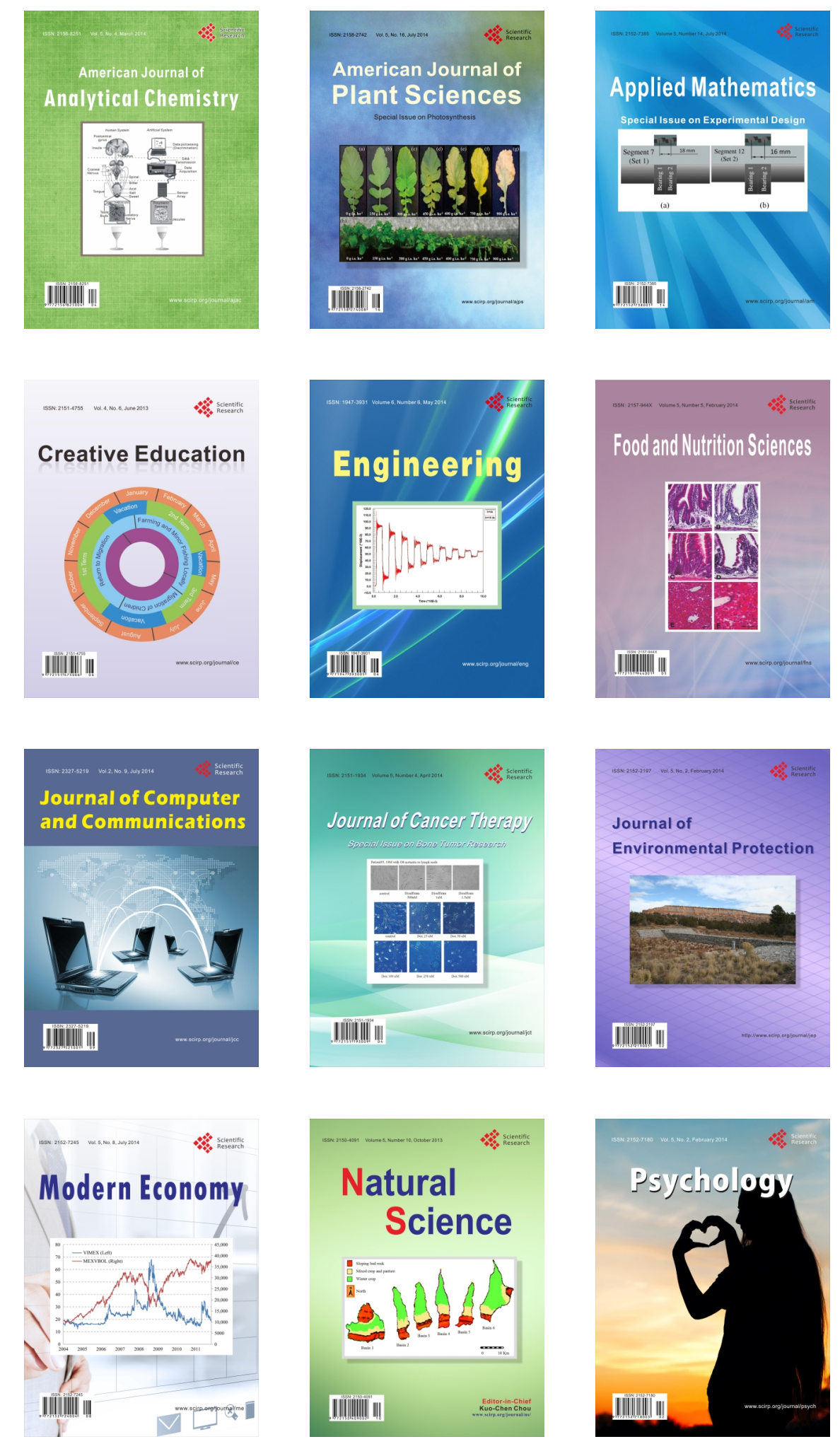